\title{
Os riscos e a prevenção para homicídios intrafamiliares no Amazonas/Brasil
}

\author{
The risks and a prevention for intrafamily homicides in Amazonas/Brazil \\ LUCILENE FERREIRA DE MELO (1) ${ }^{1}$ \\ CARLA MONTEFUSCO (D) ${ }^{2}$ \\ ${ }^{1}$ Universidade Federal do Amazonas, Manaus, AM, Brasil. \\ ${ }^{2}$ Universidade Federal do Rio Grande do Norte, Natal, RN, Brasil.
}

RESUMO - O artigo objetivou conhecer os riscos e as possíveis prevenções de homicídios intrafamiliares no Estado do Amazonas/Brasil. Para tal, foram realizadas uma revisão bibliográfica e uma pesquisa documental. Casos noticiados de homicídios, tanto os tentados quanto os consumados, no período de 2010 a 2015, foram mapeados em dois jornais do Amazonas, $A$ crítica, versão impressa, e Diário 24 horas, em versão online. Dos resultados, destaca-se a tipificação da relação familiar/parentesco entre o suposto agressor(a) e as vítima(s); o perfil etário de gênero das vítimas e a identificação de pistas para a prevenção. Conclui-se que é possível prevenir os homicídios intrafamiliares, construindo um novo saber-poder, a partir do confronto dos valores da cultura patriarcal com os princípios da educação e a cultura em Direitos Humanos.

Palavras-chave: Risco. Prevenção. Homicídio intrafamiliar. Amazonas. Brasil.

ABSTRACT - The article aimed to know the risks and possible prevention of intrafamily homicides in the State of Amazonas / Brazil. Bibliographic review and documentary research were done. Cases reported on both attempted and consummated homicides in the period from 2010 to 2015 were mapped in two Amazon newspapers, A Crítica, a printed version, and Diário 24 horas, in an online version. The results highlight the typification of the family/kinship relationship between the alleged offender(a) and the victim(s); The gender profile of the victims and the identification of clues for prevention. It is concluded that it is possible to prevent intrafamily homicides, building a new know-how, from the confrontation of the values of the patriarchal culture with the principles of education and culture in Human Rights.

Keywords: Risk. Prevention. Inmate family homicide. Amazonas. Brazil. 


\section{Introdução}

A

violência pode conduzir ao homicídio. Neste trabalho, apresenta-se essa preocupação. Um debate necessário que responde a uma lacuna da Região Norte e do Estado do Amazonas, sobretudo no tocante aos homicídios intrafamiliares, desencadeados pela violência intrafamiliar.

O Estado do Amazonas/Brasil é cenário dos acontecimentos e discussões aqui textualizadas acerca dos homicídios intrafamiliares. Amazonas é um Estado da Região Norte, situado na Amazônia brasileira, que possui $1.559 .148,890 \mathrm{~km}^{2}$ de extensão territorial, corresponde a $40,77 \%$ da Região Norte, $18,45 \%$ de todo o território brasileiro e $31 \%$ da área total da Amazônia brasileira, sendo por isso considerado o maior Estado da República Federativa do Brasil (IBGE, 2016). Ele possui 62 municípios, tendo como capital a cidade de Manaus.

O Amazonas possui concentração populacional na sua capital e em áreas urbanas. Dos 3.483 .985 habitantes do Amazonas 51,72\% residem em Manaus. Em 2010, a população da capital era de 1.802.014, com $99,5 \%$ de habitantes residindo em área urbana, também repetindo-se nos demais municípios do estado (IBGE, 2010).

No que diz respeito à violência, de acordo com o Sistema Nacional de Informações de Segurança Pública, Prisionais e sobre Drogas - Sinesp (2015), o Amazonas tem uma das maiores taxas de casos de violência doméstica na Região Norte do País, 33,5 ocorrências a cada 100 mil habitantes, mas a situação não é considerada boa em todos os estados do Norte.

Em 2014, de um total de 1.226 casos registrados na Região Norte, o Amazonas apresentou uma taxa de homicídios de 31,7\%, ocupando a segunda posição do Norte. No mesmo ano, das 13 microrregiões do Estado, a que apresentou a maior taxa de homicídios, foi a de Manaus, com 43,58\%, na sequência tem-se Rio Preto da Eva, com 42,16\%, as demais apresentaram taxas de homicídios abaixo de $20 \%$.

De acordo com Sinesp (2015), o Amazonas carece da presença de instâncias do Estado, pois a única política de redução da criminalidade violenta existente, em 2015, era o Programa Ronda no Bairro, que foi desativado em 2016.

O homicídio é considerado a forma mais brutal da interrupção da vida, sendo o crime que mais alarme social causa na sociedade (UNODC, 2013).

No Código Penal Brasileiro (1940), o homicídio é abordado nos artigos 121 a 128. O artigo 121, apresenta um extenso rol de modalidades de homicídios, iniciado pela assertiva: homicídio simples - matar alguém. Assim, definindo o homicídio como o crime contra a vida.

Os homicídios intrafamiliares são crimes previstos na legislação penal brasileira. Os crimes contra crianças e mulheres, em determinadas circunstâncias, são chamados, respectivamente, de infanticídio e feminicídio. Entretanto, a violência letal praticada por familiares e parentes não se restringe somente a esses sujeitos. No âmbito dessas relações outros sujeitos - agressores e vítimas - são encontrados.

De acordo com o Ministério da Saúde do Brasil (2002), a dinâmica familiar apresenta fatores que podem ser considerados motivadores na ocorrência da violência, podendo potencializar o homicídio. Entretanto, ao problematizar essa questão, tem-se, por um lado, essa sociabilidade da família com a produção desses motivadores, por outro, não se pode reduzir essas relações de poder que contribuem para o homicídio à família, responsabilizando-a. Raízes dessa problemática, em geral, são apontadas à cultura patriarcal.

O Ministério da Justiça (2015) utilizou o índice de cultura patriarcal para medir as desigualdades de gênero em termos de saúde, educação, trabalho e espaço político no Brasil. A violência vista sob essa ótica indica que ela não é igual para todos os membros da família. Os dados consultados do SIM/DATASUS apontam maior incidência de homicídios de mulheres, idosos e crianças.

Ressalva-se que, para o estudo da temática, há que se fazer uma leitura, assimilando a violência na vivencia cotidiana, colocando em pauta um jogo de dominação que intenciona sujeitar a outra pessoa, seja qual for a relação, retirando-Ihe a autonomia e a liberdade, ou seja, há que se problematizar a forma negativa do uso do poder.

Ancora-se, neste trabalho, a compreensão das relações de poder na perspectiva de Foucault a um reconhecimento que tudo na sociedade está submetido a um jogo de forças. Para Foucault, as relações 
de poder são: "relações entre parceiros [...] um conjunto de ações que se induzem e se respondem umas às outras" (FOUCAULT, 1995, p. 240). Nesse sentido, o poder tem várias nuances, pois "em si mesmo ele não é uma violência". A questão está em "como se exerce o poder", ou seja, ele deve ser exercido nas relações entre sujeitos no exercício da liberdade, com autonomia. Por isso, também importa considerar o saber-poder, o dispositivo disciplinar que consubstancia essa relação.

Na violência intrafamiliar, a forma de saber-poder que negativamente vem incidindo em homicídios é a cultura patriarcal. A violência nega o aspecto relacional entre sujeitos. De modo que diante da desigualdade de gênero, por exemplo, dispositivo de verdade da cultura patriarcal, as relações de poder na esteira de Foucault não se processam, pois o "outro" partícipe do processo não é concebido com a liberdade necessária para corresponder na relação, e o efeito disso é o "outro" sujeito impedido de "governar" e aceitar ser governado.

Este artigo teve por objetivo conhecer os riscos e as possibilidades de prevenção de homicídios intrafamiliares, entre elas tem-se a educação em direitos humanos. Foram feitas revisão bibliográfica e pesquisa documental. Casos noticiados de homicídios, tanto os tentados quanto os consumados, no período de 2010 a 2015, foram mapeados em dois jornais do Amazonas, A crítica, versão impressa, e Diário 24 horas, em versão online. As análises dos dados estão baseadas na análise do discurso em Foucault.

Este trabalho é um dos resultados da pesquisa "Homicídios Intrafamiliares no Estado do Amazonas: um estudo para (re) criar estratégias de prevenção na esfera pública", em desenvolvimento no âmbito do estágio pós-doutoral, na Universidade Federal do Rio Grande do Norte.

Registra-se aqui um reconhecimento ao utilizar o jornalismo impresso e online como fonte de dados. Com base em Foucault (2004), a mídia é um recurso social que possui funções ideológicas, enraizadas na estrutura social. Esse saber-poder é expresso, entre outras coisas, na prática da escrita, produtora de verdades. Embora feita essa observação, o fácil acesso aos dados deve ser considerado, possibilitando reflexões como esta.

A partir desse discurso político-midiático buscam-se os riscos oriundos do poder inerentes aos sujeitos no contexto intrafamiliar, pois na perspectiva de Foucault (2004), o poder está submerso em todas as relações sociais, são micropoderes. A família não está imune.

\section{Desenvolvimento}

\subsection{Risco e prevenção como preocupação institucional}

Ao tratar sobre os riscos e a prevenção de homicídios intrafamiliares, considera-se que, em geral, essa ocorrência é uma consequência de um ambiente com relações pautadas no uso da violência, manifestas na linguagem, nos gestos e nas atitudes no cotidiano dos sujeitos, familiares e parentes que compõem esse círculo.

Os riscos e a prevenção têm sido objeto de atenção de organismos internacionais e nacionais, constituindo-se em uma preocupação mundial a minimização das ocorrências de violências. Por fatores de risco entende-se,

Fator que aumenta a probabilidade de incidência ou os efeitos negativos de crimes ou violências, mas não determina a incidência ou os efeitos negativos de crimes e violências. Quanto maior a presença de fatores de risco, e menor a presença de fatores de proteção, maior a probabilidade de incidência e de efeitos negativos de crimes e violências (MINISTÉRIO DA JUSTIÇA DO BRASIL, 2005, p. 52).

A partir dessa compreensão, os riscos e a prevenção são peças essenciais sobre maior ou menor incidência de homicídios. Deve-se considerar também que os crimes ou violências possuem outros determinantes associados. Outro aspecto a se destacar nessa acepção, é o vocábulo "probabilidade", ou seja, a presença por si só do risco e da ausência de prevenção não significa a confirmação do crime ou da 
violência. Por outro lado, a presença dos riscos sinaliza um ambiente negativo que associado a outros fatores podem desencadear uma ocorrência grave ou letal.

Dados de organizações como a Organização Mundial da Saúde - OMS (2014) e da Secretaria Nacional de Segurança Pública - SENASP (2015) apontam que, a acessibilidade às armas de fogo associada a um ambiente permeado por conflitos, aumenta o perigo de um homicídio, por exemplo.

No Brasil, a prevenção dos homicídios vem recebendo atenção do Estado. Políticas e programas possuem objetivos voltados para a redução de crimes (SENASP, 2015, p. 6). Cita-se o Pacto Nacional pela Redução de Homicídios - PNRH, lançado em 2015 como uma iniciativa nessa direção (SINESP, 2015).

Estudos de Entidades como o da United Nations Office on Drugs and Crime (UNODC) sobre homicídios no mundo alega a possibilidade de diminuição dos homicídios, desde que os "facilitadores" desses passem a ser objeto de atenção de políticas preventivas.

Son diversos los factores que intervienen en el proceso que lleva a la comisión de un homicidio. Desde la disponibilidad de un arma (o la falta de ésta) hasta el uso de sustancias psicoactivas, que podrían actuar como "facilitadores" del homicidio, tales factores pueden determinar patrones y niveles de este delito; cuando se les presta atención a través de políticas de prevención, los homicidios pueden disminuir (UNODC, 2013, p. 5).

A institucionalização é o caminho para o enfrentamento, promovendo a observância nos intervenientes associados à ocorrência de homicídios e na implementação de medidas preventivas.

Nessa direção, a Organização Mundial de Saúde (OMS, 2014), constata um número considerável de atividades de prevenção da violência em todo o mundo, mas também aponta lacunas dessas iniciativas em todo o mundo. A OMS sugere um plano de ação nacional, recursos orçamentários, responsabilidades e processos de monitoramento bem definidos para a prevenção da violência.

Os riscos e as possibilidades de prevenção em relevo, neste trabalho, são aqueles relacionados à violência intrafamiliar, representada aqui pelos homicídios. Neles aparecem os riscos específicos às tipologias intrafamiliares definidas pela relação familiar/parentesco entre ofensor(a) e vítima(s), designadas por parricídios, filicídios, fratricídios e nos homicídios a outros familiares/parentes encontrados nas fontes de dados utilizados.

O homicídio intrafamiliar é uma violência letal que ocorre no círculo das relações familiares e de parentesco. Esse entendimento é baseado em Mascoli (2015):

[...] será todo aquele cujo culminar da violência intrafamiliar termina em homicídio, uma morte violenta, com intencionalidade, em que o agente ofensor e a vítima estabeleceu ou estabelecem entre si laços familiares ou de parentesco. Por laços familiares, entendem-se os laços estabelecidos por consanguinidade, descendente de um ancestral comum. Por laços de parentesco entendem-se os laços estabelecidos por afinidade, por via de aliança ou dela resultante (MASCOLI, 2015, p. 5).

Nessa concepção de Mascoli (2015), o ápice da violência intrafamiliar é o homicídio. A possibilidade de homicídio aumenta na medida em que o contexto familiar é violento. Nesse universo, as relações são pautadas por laços familiares e de parentescos, mas nem sempre pela afetividade e pela segurança.

Aparentemente, o homicídio cometido no âmbito da família contra outro ente familiar apresenta uma contradição ao papel social atribuído às relações familiares, a de protetora, nunca de agressora. Entretanto, quando se considera a cultura da dominação, do controle, de disputas, entre outros que impera na sociedade, a contradição maior está em não reconhecer na vida cotidiana e na família, a presença da cultura da violência, que pode levar a morte.

Nesse sentido, entende-se o homicídio intrafamiliar como uma ação produzida em meio a relações de poder conduzidas por forças negativas, que encontra sintonia em um sujeito, o qual, em um momento de sua vida, ultrapassa as fronteiras legais, éticas e morais do direito à vida do outro ser humano. Esse ato 
extremo condiz com o tratamento repressivo e punitivo que a sociedade responde ao trato da violência. Ele também evidencia que os dispositivos de controle e de punição vigentes são contraditórios, pois geram mais violência, e são impotentes, pois não surtem o efeito de combatê-la.

\subsection{Tipos de homicídios intrafamiliares noticiados no Amazonas/Brasil}

$\mathrm{Na}$ literatura, o crime "homicídio intrafamiliar" inclui tipologias intrafamiliares de acordo com as relações estabelecidas entre agressor e vítima. No Brasil, o infanticídio possui essa característica. No Código Penal Brasileiro, tem sua definição no artigo 123, que é: "Matar, sob a influência do estado puerperal, o próprio filho, durante o parto ou logo após, tipificando um ato somente possível de ser praticado pela mãe, tipificando a relação entre agressora e vítima" (BRASIL, 2015, p. 30).

O feminicídio, crime tipificado no Brasil, pela Lei 13.104/15, que foi introduzido no Código Penal como delito hediondo, é aplicado quando a vítima é uma mulher e apresenta as condições postas pela lei:

§ 2o A Considera-se que há razões de condição de sexo feminino quando o crime envolve: I - violência doméstica e familiar; II - menosprezo ou discriminação à condição de mulher (BRASIL, 2015, p. 1).

Esse delito, o feminicídio, aparece com denominação jurídica própria no Código Penal, possui particularidades que o diferencia do simples homicídio de mulheres, no qual fica muito bem definida a tipificação da vítima, a condição feminina, a autoria do crime pode ser inclusive de uma outra mulher.

Nem toda mulher que é assassinada é um feminicídio do ponto de vista da legislação brasileira, pois esse tipo penal para ser considerado deve apresentar as condições estabelecidas na lei. Neste trabalho, todas as mulheres que sofreram violência intrafamiliar letal podem ser enquadradas como vítimas de feminicídio.

Os homicídios cometidos por parentes a outros elementos da família são definidos por Mascoli (2015) como: o filicídio pode ser perpetrado pelo pai, pela mãe ou por ambos os progenitores; entre irmãos (fratricídio); um filho que mata o pai (parricídio) ou a mãe (matricídio), mais do que um homicídio dentro da mesma família de um parceiro e de um filho (ou vários filhos), acompanhado ou não do suicídio do indivíduo que cometeu os homicídios (familicídio) (MASCOLI, 2015, p. 51).

No Brasil, desde 2015, há um projeto de lei tramitando no Senado Federal para alterar o Código Penal e o art. 1ㅇ da Lei no 8.072, de 25 de julho de 1990, a fim de transformar o homicídio de pessoas idosas em crime hediondo, caracterizando como idosicídio. Mas, neste trabalho, preferimos categorizar o homicídio cometido contra a pessoa idosa, a partir da relação autor-vítima e da distinção em relação às vítimas do sexo feminino.

Esse procedimento foi adotado a partir do entendimento de Mascoli (2015), a qual defende a ideia que há riscos específicos às tipologias intrafamiliares definidas pela relação familiar/parentesco entre ofensor(a) e vítima(s), logo os riscos requerem prevenção diferenciadas.

Outro elemento que serviu de referência para a organização da exposição da discussão está relacionado com a organização das políticas sociais no Brasil orientadas por segmentos populacionais, de gênero ou faixa etária, por exemplo, criança e adolescente, jovem, mulher, idoso, entre outros.

No levantamento realizado nos dois jornais foram encontrados quarenta e um casos publicados sobre homicídios intrafamiliares; quarenta e sete vítimas; e, quarenta e dois supostos(as) autores(as). Isso porque alguns casos apresentavam mais de uma vítima e mais de um(a) suposto(a) autor(a), certamente, esses números representam apenas uma amostra da quantidade real de crimes dessa natureza, considerando a fonte consultada.

No Quadro 1, as informações foram organizadas no sentido de podermos visualizar três questões: na coluna tipificação estão as tipologias intrafamiliares com a relação familiar/parentesco entre suposto agressor(a) e vítima(s); em seguida o perfil etário de gênero das vítimas. Embora, tenha sido feita essa tipificação, lembra-se que o Código Penal Brasileiro caracteriza com denominação jurídica, dentre os tipos encontrados, somente o feminicídio. 
Observa-se, no Quadro 1, que o crime praticado contra a vida atingiu mais pessoas do sexo feminino. O ambiente intrafamiliar é território considerado de risco para as mulheres, de todas as idades. Nele, essas constituem a população vulnerável.

Em relação a faixa etária, os riscos de homicídios contra mulheres desde a primeira idade são constantes, mas a maior incidência está na faixa dos 30 aos 59 anos, sobretudo de vítimas de homicídios, cujo suposto agressor as vítimas estavam ou tiveram uma relação conjugal.

No Quadro 1, na coluna da tipificação, têm-se as informações das vítimas de feminicídio cujo suposto agressor as vítimas tinham ou tiveram uma relação conjugal, são ex-maridos e ou companheiros, maridos ou companheiros. Dos doze casos de feminicídios todos os supostos autores são do gênero masculino. Esses tipos de crime podem ser considerados os tipos clássicos de feminicídios: mulheres mortas por parceiros íntimos, em uma relação heterossexual.

Quadro 1 - Tipificação de homicídios tentados e consumados no Amazonas por faixa etária e gênero

\begin{tabular}{|c|c|c|c|c|c|c|c|c|c|c|}
\hline \multirow{3}{*}{ Tipificação } & \multicolumn{8}{|c|}{ Perfil etário e de gênero das vítimas } & \multirow{2}{*}{\multicolumn{2}{|c|}{$\begin{array}{l}\text { Total por gênero e } \\
\text { relação autor-vítima }\end{array}$}} \\
\hline & \multicolumn{2}{|c|}{ Até 14 anos } & \multicolumn{2}{|c|}{15 a 29 anos } & \multicolumn{2}{|c|}{30 a 59 anos } & \multicolumn{2}{|c|}{ Acima de anos } & & \\
\hline & M & FF & M & $\mathbf{F}$ & M & FF & M & $\mathbf{F}$ & M & $\mathbf{F}$ \\
\hline Filicídio & 6 & 8 & 2 & 1 & 0 & 0 & 0 & 0 & 8 & 9 \\
\hline Feminicídio (conjugal) & 0 & 0 & 0 & 4 & 0 & 8 & 0 & 0 & 0 & 12 \\
\hline Matricídio* & 0 & 0 & 0 & 0 & 0 & 3 & 0 & 1 & 0 & 5 \\
\hline Parricídio* & 0 & 0 & 0 & 0 & 1 & 0 & 2 & 0 & 4 & 0 \\
\hline Fratricídio & 1 & 0 & 3 & 0 & 0 & 0 & 0 & 0 & 4 & 0 \\
\hline Homicídio intrafamiliar & 0 & 0 & 0 & 1 & 2 & 1 & 0 & 1 & 2 & 3 \\
\hline & & & & & & & & & 18 & 29 \\
\hline Total por idade e gênero & 7 & 8 & 5 & 6 & 3 & 12 & 2 & 2 & & \\
\hline
\end{tabular}

* 1 vítima de matricídio e 1 de parricídio não tiveram a idade divulgada, não contaram no item faixa etária, mas foram incluídas no total por gênero e relação autor-vítima.

Fonte: Jornais do Amazonas/Brasil (2010 -2015).

As demais vítimas do gênero feminino foram distribuídas, segundo o procedimento adotado, na coluna de filicídios, de matricídio e de homicídios intrafamiliares, estando nesta última coluna os casos cuja relação com o suposto agressor(a) não possui uma tipificação definida na literatura utilizada, totalizando 29 vítimas.

Dos vinte e nove casos de feminicídios, doze deles os supostos autores tiveram ou tinham uma relação íntima com a vítima; nove casos de filicídios com vítimas femininas cujo suposto(a) agressor(a) são os pais e ou padrastos/madrastas; cinco casos de matricídios, mães assassinadas pelos filhos(as); e três são vítimas de parente ou familiar, caso de netos, sobrinhos e primos, por exemplo.

No Brasil, de acordo com o mapa da violência 2015 (WAISELFISZ, 2015), a proporção de feminicídio considerando a relação autor-vítima corresponde a sete quando envolve a relação autor-vítima-familiar e, quatro quando a relação é autor-vítima-parceiro íntimo.

Nos filicídios têm-se os pais, compreendendo esses como mãe, pai, padrasto e madrastas, como supostos autores que negaram o direito à vida dos seus filhos, independentemente da idade. Nos casos identificados nos jornais, dez foram cometidos por pai e ou padrasto; quatro pelos pais e três somente pela mãe. Há um predomínio como suposto autor, o familiar do sexo masculino. Entretanto, as mulheres também fazem composição com os maridos ou companheiros, participando em sete casos.

Tem-se um cenário complexo, ocorrendo num espaço considerado privado, mas que requer intervenção. Diante disso, as diferentes modalidades de violência praticadas, buscando assegurar o direito à vida às pessoas que constituem a família. 


\section{Tipologias intrafamiliares de homicídios: riscos e possíveis prevenções}

A violência intrafamiliar expõe diferentes indivíduos ao risco de adoecer ou morrer. Isso foi constatado nas circunstâncias que deflagraram os quarenta e um casos de homicídios estudados. A partir das matérias jornalísticas, foi possível fazer a identificação de variáveis que sinalizam pistas para o enfrentamento pela prevenção.

Nos homicídios, expostos pelos jornais, pode-se verificar mais de um risco. Para cada um dos homicídios foi selecionado, apenas um risco para esta exposição, utilizando como critério o que mais apresentava em comum com os demais casos, com isso foi feito a categorização das variáveis.

No Quadro 2, está alocada a sistematização dos riscos de homicídios por tipificação de acordo com a relação dos supostos(as) autores(as) com as vítimas. Observa-se que a violência doméstica como um risco de homicídio, atravessa as tipificações que possuem vítimas do sexo feminino (feminicídio, filicídio, matricídio e outros homicídios intrafamiliares).

Quadro 2 - Riscos identificados nos casos homicídios intrafamiliares noticiados

\begin{tabular}{|c|c|}
\hline Riscos identificados de homicídios & Total \\
\hline 1. Risco de feminicídio oriundos de relação conjugal & 12 \\
\hline Aspectos associados com o processo de separação conjugal (antes, durante e depois) & 5 \\
\hline Convivência com a violência doméstica & 4 \\
\hline Violência doméstica associada ao álcool e outras drogas & 3 \\
\hline 2. Risco de filicídios & 17 \\
\hline Vitimização em decorrência da exposição à violência conjugal dos pais & 1 \\
\hline Vitimização em decorrência do processo de separação conjugal dos pais & 4 \\
\hline Violência dos pais com os filhos & 5 \\
\hline Violência dos pais com os filhos associada ao álcool e outras drogas & 4 \\
\hline Comprometimento psicológico/psiquiátrico da mãe & 1 \\
\hline Negligência dos pais & 2 \\
\hline 3. Riscos de matricídios & 5 \\
\hline Recusa da exploração financeira e econômica & 2 \\
\hline Comprometimento psicológico/psiquiátrico dos filhos & 2 \\
\hline Violência doméstica associada ao álcool e outras drogas & 1 \\
\hline 4. Riscos de parricídios & 4 \\
\hline Interesse nos recursos econômicos, financeiros e patrimoniais do pai & 2 \\
\hline Comprometimento psicológico/psiquiátrico dos filhos & 1 \\
\hline Conflitos familiares associados ao álcool e outras drogas & 1 \\
\hline Intervenção em violência conjugal dos pais & 1 \\
\hline 5. Riscos de fratricídios & 4 \\
\hline Comprometimento psicológico/psiquiátrico & 1 \\
\hline Conflitos familiares associados ao álcool e outras drogas & 3 \\
\hline 6. Riscos de outros homicídios intrafamiliares & 5 \\
\hline Intervenção em violência conjugal de filhos & 2 \\
\hline Tomar conhecimento ou denunciar atos ilícitos e ou contravenções de familiar & 3 \\
\hline
\end{tabular}

Fonte: Jornais do Amazonas/Brasil (2010-2015).

A Lei no 11.340/06, Lei Maria da Penha no art. 5o. configura violência doméstica e familiar contra mulher como: 
[...] qualquer ação ou omissão baseada no gênero que the cause morte, lesão, sofrimento físico, sexual ou psicológico e dano moral ou patrimonial, amplia ainda nos incisos I, II e III, respectivamente, os termos "âmbito da unidade familiar", "âmbito da família" e em qualquer relação íntima de afeto, onde se estabelecem as formas de violências (BRASIL, 2006, p. 13).

Lembra-se que na violência doméstica admite-se outros supostos agressores às mulheres, além das relações de afetos ou familiares, tratado nos incisos I a III, do art. 5ำ, da Lei Maria da Penha, como agregados esporádicos e empregados, os quais não foram considerados neste trabalho.

Sobre a violência doméstica, de natureza conjugal, no estudo realizado por Castanho (2013), em Portugal, a presença da violência é uma predisposição ao homicídio. Há uma compreensão de que na qualidade das relações familiares estão os indícios, tensão permanente, dificuldades de lidar com conflitos, entre outros.

Mas, pontua-se que, sobretudo, há uma dificuldade em "reconhecer" a presença da violência familiar, no que diz respeito a extensão conceitual do que ela seja. De acordo com Waiselfisz (2015), 48,7\% dos atendimentos por violências registrados pelo Sistema único de Saúde no Brasil, em 2014, recaem sobre a violência física, e somente $23 \%$ é de violência psicológica. Isso demonstra ainda uma concepção limitada dos diferentes tipos de violência possíveis no círculo familiar ou doméstico.

Ainda, de acordo com Waiselfisz (2015), a reincidência da violência recai sobre a metade dos atendimentos femininos e, apenas a metade desses atendimentos têm algum tipo de encaminhamento para uma ou mais instituição.

Esses dados evidenciam que o atendimento, para as vítimas de violência intrafamiliar e doméstica, ainda demanda fortalecimento no serviço de saúde, compromisso e colaboração em relação ao estímulo à prevenção. Isso porque, o suposto agressor(a) repetidas vezes marca a vítima, por meio de uma conduta agressiva, e não é denunciado nem pela família, nem por profissionais. Aqui tem-se um aspecto crucial da situação: um "aparente" pacto de aceitação da violência.

Apesar dos casos de homicídios intrafamiliares em sua maioria serem mulheres, há dezoito casos de homens que foram vitimados, os quais não estão sob a tutela jurídica da Lei Maria da Penha. Por essa razão, neste trabalho, utiliza-se a discussão a partir da violência intrafamiliar, pois nem sempre, nesse âmbito, somente as mulheres são vulneráveis, depende das relações de poder estabelecidas entre familiares e parentes.

A presença de violência intrafamiliar é um risco. Nesse ambiente, os filhos foram vitimados em decorrência da exposição à violência conjugal, em alguns casos, desde o título das matérias jornalísticas pôde-se inferir isso: "Atira em esposa e mata criança de 2 anos".

Os filicídios ocorreram em ambientes conturbados pela violência, os riscos são, em sua maioria, a presença da violência, em geral, com a cumplicidade de seus membros. Nesse contexto, subjetividades são construídas, mobilizam ações em relação ao outro parente ou familiar, essas nem sempre em favor da vida. Dessa forma, as famílias com essas predisposições constituem-se em famílias de risco.

No Quadro 2, observa-se que a presença de agentes potencializadores como álcool e outras drogas associadas à violência doméstica aparece como determinante nos casos encontrados de fratricídios. Nas demais tipificações, essa presença existe, mas não em sua maioria. O que nos remete a uma leitura: a violência presente de modo latente é dinamizada por um jogo de poder, em uma relação assimétrica, conduzindo um sujeito a utilizar a sua força em direção à morte.

Fonseca, Galduróz, Tondowskil et al. (2009) defendem a ideia de que há uma necessidade de iniciativas que ampliem o auxílio às famílias, incluindo a busca ativa dos casos, por exemplo, por meio do Programa Saúde da Família. Há necessidade de ações preventivas na interseção das áreas da violência doméstica e da dependência química.

No Brasil, a rede de atendimento à mulher em situação de violência está dividida em quatro principais setores/áreas (saúde, justiça, segurança pública e assistência social) (SPM/PR, 2011, p. 14). 
Pondera-se aqui em relação ao serviço de saúde, de segurança pública e assistência social, estes nem sempre são os primeiros a saberem sobre as possíveis situações de violência intrafamiliar, demandando que outras instituições devem estar preparadas para identificar e dar encaminhamento para a atenção às vítimas.

No Quadro 2, observa-se que a intervenção em violência conjugal também pode culminar em homicídio, ela foi risco de parricídio e homicídio intrafamiliar. Os pais, os filhos são chamados para intervir. De acordo com Zuma (2004), comumente, são as pessoas da nossa rede mais próxima, afetiva ou espacialmente a prestar uma primeira ajuda ou orientação na ocorrência desses casos. $O$ autor postula a preparação de lideranças comunitárias para lidar com esses conflitos, capacitação que pode ser estendida à família (ZUMA, 2004, p. 35).

No Quadro 2, observa-se que o comprometimento psicológico/psiquiátrico foi predominante nos matricídios. Para Dreyer; Picon; Falceto (2010) a existência de algum transtorno mental nos casos de matricídio não seriam homicídio reativos, considerados como resposta a abusos sofridos (DREYER; PICON; FALCETO, 2010, p. 4). Por outro lado, isso evidencia a exposição ao risco do cuidador de pessoas com essas condições de saúde.

Dentre os riscos nos parricídios figuram aqueles vinculados aos interesses dos filhos(as) nos recursos financeiros e econômicos dos pais, esses repetindo-se nos matricídios. De acordo com Lotti (2013), esse risco foge do padrão que, em geral, é atribuído a esses crimes, é mais comum a loucura ser vinculada aos parricidas ou matricidas, inclusive, a autora lembra o clássico caso discutido por Foucault: "Eu, Pierre Rivière, que degolei minha mãe, minha irmã e meu irmão: um caso de parricídio do século XIX". Para a autora, essa associação com a loucura está na repulsa que esse tipo de crime causa à sociedade. Entretanto, cada caso precisa ser melhor analisado.

No Quadro 2, ainda se observa que tomar conhecimento ou denunciar contravenções de familiares é um risco para homicídios. Esse dado nos remete a pensar sobre a confiança que a sociedade ainda deposita no sistema penal, como forma de punir e corrigir o indivíduo transgressor. Isso repercute tanto para o denunciante quanto para o denunciado. Para o denunciante, denunciar atos ilícitos, é um ato de cidadania, por não ser conivente com a ação cometida. Por sua vez, para o denunciado, o denunciante é um delator, e, o encarceramento, não é, exatamente, um lugar para onde ele queira ir; por isso, testemunhas de delitos, muitas vezes, são assassinadas, para que outros crimes não sejam descobertos, como ocorreu com três vítimas dos casos identificados nos jornais.

Diante dos dados expostos no Quadro 2, os riscos de homicídios situaram-se em diferentes momentos nas relações familiares, processos de separação, recusa de exploração econômica, intervenção em um conflito familiar específico; bem como em atos contínuos de violência entre o casal, dos pais para com os filhos, entre outros.

Depara-se, por um lado, com vítimas e supostos(as) autores(as) imersos em um cotidiano cúmplice da cultura da violência. Sujeitos que, em suas histórias de vida, possivelmente, não tiveram a oportunidade de colocar-se diferente diante de situações conflituosas. Nesse cenário, a insegurança está na tensão permanente que não é cessada, porque a resposta para os conflitos é creditada na violência, gerando mais violência. $\mathrm{O}$ desafio colocado para a sociedade seria trabalhar no declínio desses gestos, expressos nas vitimizações produzidas, sobretudo na ruptura da cumplicidade e na prevenção da violência.

A materialidade dessa realidade pode ser remetida às marcas do dispositivo de controle-dominação na vida cotidiana. Tais marcas podem ser relacionadas à mecânica do poder, que consiste em: "no ponto em que o poder encontra o nível dos indivíduos, atinge seus corpos, vem se inserir em seus gestos, suas atitudes, seus discursos, sua aprendizagem, sua vida quotidiana" (FOUCAULT, 2004, p. 74).

De acordo com Zuma (2004), ao problematizar a violência intrafamiliar também pressupõe problematizar os valores da cultura patriarcal na família, significa também trazer para o centro da atenção pública a família.

No que tange à prevenção, nas diretrizes das medidas integradas de prevenção da Lei Maria da Penha, encontra-se o aspecto educacional, tanto no âmbito formal quanto informal, que pode ser desenvolvido por organismos governamentais e não governamentais. 
Nessa direção, as ações de educação como ação preventiva ainda são poucas. Educar brasileiros e brasileiras na ótica dos direitos humanos para a construção de uma cultura de proteção e promoção dos direitos humanos é o desafio posto na sociedade brasileira, como uma política pública, independentemente de ser um agressor(a), pois "aceitar" a conduta violenta expressa uma cumplicidade, explicada de diversas formas essa anuência, mas que somente faz perdurar a cultura da violência.

Para Foucault (2004), o poder é difuso. A resistência coexiste a ele. Mas precisa de condições para isso. Reverter esse dispositivo de controle-dominação na família é possível, conforme as palavras de Foucault (2004), "jamais somos aprisionados pelo poder: podemos sempre modificar sua dominação em condições determinadas e segundo uma estratégia precisa" (FOUCAULT, 2004, p. 136).

A partir dos elementos da educação e da cultura em Direitos Humanos é possível pensar um novo saber-poder, com um discurso que devolve ao sujeito essa possibilidade de ter uma possível liberdade e autonomia, um sujeito que possa ter um outro contraponto na reflexão sobre a violência. No Programa Nacional de Direitos Humanos (PNDH-3) (2010) ela é assim concebida:

A educação e a cultura em Direitos Humanos visam à formação de nova mentalidade coletiva para o exercício da solidariedade, do respeito às diversidades e da tolerância. Como processo sistemático e multidimensional que orienta a formação do sujeito de direitos, seu objetivo é combater o preconceito, a discriminação e a violência, promovendo a adoção de novos valores de liberdade, justiça e igualdade (BRASIL, 2010, p. 185).

Ela se propõe a formar uma nova mentalidade e uma adoção de novos valores. Essa educação coloca o sujeito diante de um "outro", diferente de si, mas com igual valor.

\section{Considerações finais}

Este artigo teve por objetivo conhecer os riscos e verificar as possibilidades de prevenção, dentre essas a educação em direitos humanos, no sentido de prevenir homicídios intrafamiliares.

A partir das matérias jornalísticas, foi possível fazer a tipificação da relação familiar/parentesco entre suposto agressor(a) e vítima(s); o perfil etário de gênero das vítimas; e a identificação de variáveis que sinalizam pistas para o enfrentamento pela prevenção.

Os riscos de homicídios figuram em diferentes momentos nas relações familiares e em atos contínuos de violência entre o casal, dos pais para com os filhos, entre irmãos e outros familiares ou parentes.

Os dados obtidos evidenciam que, no ambiente intrafamiliar, as mulheres, de todas as idades, constituem a população vulnerável aos homicídios. Mas, os homens também aparecem como vítimas nesse contexto, em diferentes faixas etárias, sendo predominante até 14 anos, indicando que os meninos são vítimas da cultura patriarcal, reproduzindo-a posteriormente, mantendo o círculo vicioso da violência.

A cultura da violência vem orientando as relações familiares. Os homicídios intrafamiliares inserem-se nos mecanismos de controle-dominação enraizados nos valores da cultura patriarcal. Diante disso reforçase a importância da educação em direitos humanos para a construção de novos patamares civilizatórios. Instiga-se um confronto entre esses referenciais.

O confronto do saber-poder que desvaloriza os direitos da pessoa humana por outro que valorize esse direito, abre a possibilidade de outro modo de ser e de viver aos seres humanos, sem violência.

\section{Referências}

BRASIL. Ministério da Saúde. Secretaria de Políticas de Saúde. Violência intrafamiliar: orientações para prática em serviço. Brasília: Ministério da Saúde, 2002. 
BRASIL. Código Penal. Decreto-Lei no 2.848, de 7 de dezembro de 1940. Disponível em: http://legis.senado.gov.br/legislacao. Acesso em: 10 set. 2016.

BRASIL. Lei no 10.973, de 2 de dezembro de 2004. Disponível em: http://legis.senado.gov.br/legislacao. Acesso em: 10 set. 2016.

BRASIL. Lei Maria da Penha: Lei no 11.340, de 7 de agosto de 2006, que dispõe sobre mecanismos para coibir a violência doméstica e familiar contra a mulher. Brasília, 2006. Disponível em: http://legis.senado.gov.br/legislacao. Acesso em: 10 set. 2016.

BRASIL. Secretaria de Direitos Humanos da Presidência da República. Programa Nacional de Direitos Humanos (PNDH-3). Brasília: SEDH/PR, 2010. Disponível em: www.direitoshumanos.gov.br.

CASTANHO, António. Análise Retrospectiva de Homicídios ocorridos em Relações de Intimidade. Núcleo de Estudos e Análise Prospetiva em Segurança Interna (NEAPSI), Lisboa, Portugal, 2013.

CERQUEIRA, Daniel et al. Atlas da Violência 2016. In: Ipea e FBSP. Fórum Brasileiro de Segurança Pública, Brasília, março de 2016. (Nota Técnica, 17).

DREYER J. R.; PICON, F. A.; FALCETO, O. G. Matricídio: uma breve revisão. Revista Brasileira de Psicoterapia, Porto Alegre, v. 12, n. 2-3, p. 174-183, 2010.

ESCRITÓRIO DAS NAÇÕES UNIDAS SOBRE DROGAS E CRIME (UNODC). Estudio mundial sobre el Homicidio. Resumen ejecutivo, 2013.

FÉRRER, Elmano. Senado Federal o Projeto de Lei 373/2015. Para tornar o homicídio contra o idoso crime hediondo. Disponível em: http://www12.senado.leg.br/. Acesso em: 10 set. 2016.

FONSECA, A. M.; GALDURÓZ, J. C.; TONDOWSKI, C. S. Noto AR. Padrões de violência domiciliar associada ao uso de álcool no Brasil. Revista de Saúde Pública, São Paulo, v. 43, n. 5, p. 743-9, 2009. https://doi.org/10.1590/S003489102009005000049

FOUCAULT, M. O Sujeito e o Poder. In: RABINOW, P.; DREYFUS, H. Michel Foucault. Uma trajetória filosófica. Para além do estruturalismo e da hermenêutica. Rio de Janeiro: Forense Universitária. 1995.

FOUCAULT, M. Microfísica do poder. Introdução e revisão técnica de Roberto Machado. Rio de Janeiro: Graal, 2004.

IBGE. Censo Demográfico. Brasília: IBGE, 2010.

IBGE. ÁreaTerritorial Brasileira. 2016. Disponível em: http://www.ibge.gov.br/home/geociencias/cartografia/default_ territ_ara.shtm. Acesso em: dez. 2016.

LOTTI, Laura Marazita. Os crimes de parricídio e matricídio: análise das decisões do Tribunal de Justiça do Rio Grande do Sul. Monografia apresentada ao Departamento de Ciências Penais da Faculdade de Direito da Universidade Federal do Rio Grande do Sul. Porto Alegre, 2013.

MASCOLI, Luisa Maria Carreira Ferreira. O homicídio intrafamiliar: contributos para a avaliação de risco. Tese. Universidade Fernando Pessoa. Porto 2015.

MINISTÉRIO DA JUSTIÇA DO BRASIL. Guia de Prevenção do Crime e da Violência, 2005.

ORGANIZAÇÃO MUNDIAL DE SAÚDE. Relatório Mundial sobre a Prevenção da Violência 2014. Tradução do Núcleo de Estudos da Violência da Universidade de São Paulo. São Paulo, 2015.

SINESP. Cíntia Liara Engel et al. Diagnóstico dos homicídios no Brasil: subsídios para o Pacto Nacional pela Redução de Homicídios. Brasília: Ministério da Justiça, Secretaria Nacional de Segurança Pública, 2015.

SECRETARIA DE POLÍTICAS PARA AS MULHERES. PRESIDÊNCIA DA REPÚBLICA (SPM/PR). Rede de enfrentamento à violência contra as mulheres. Brasília, 2011. (Coleção enfrentamento à Violência contra as mulheres).

WAISELFISZ, Julio Jacobo. Mapa da violência 2015: homicídio de mulheres no Brasil. Brasília, DF, 2015. Disponível em: www.mapadaviolencia.org.br. 
ZUMA, Carlos Eduardo A violência no âmbito das famílias: identificando práticas sociais de prevenção. Disponível em: http://www.noos.org.br/acervo/A-violencia-no-ambito-das-familias-identificandopraticas-sociais-de-prevencao.pdf. Acesso em: 03 nov. 2016.

Recebido em: 26/9/2018

Aprovado em: 9/4/2019.

Publicado em: 10/10/2019.

Correspondência para:

Lucilene Ferreira de Melo

Universidade Federal do Amazonas, ICHL

Departamento de Serviço Social

Campus Universitário Coroado

Av. General Rodrigo Octavio Jordão Ramos, 3000 - Setor Norte

69077-000, Manaus, AM, Brasil

\section{Autoras:}

LUCILENE FERREIRA DE MELO

Doutora em Ciências Biológicas pelo Instituto Nacional de Pesquisas da Amazônia (INPA), AM, Brasil.

Professora do Departamento de Serviço Social e do Programa de Pós-Graduação em Serviço Social e Sustentabilidade na Amazônia da Universidade Federal do Amazonas (PPGSS/UFAM), Manaus, AM, Brasil.

Orcid: https://orcid.org/0000-0002-8667-1846

E-mail: lucilenefmelo@yahoo.com.br

CARLA Montefusco

Doutora em Ciências Sociais pelo Programa de Pós-Graduação em Ciências Sociais da Universidade Federal do

Rio Grande do Norte (PPGCS/UFRN), Natal, RN, Brasil. Professora do Programa de Pós-Graduação em Serviço Social da

Universidade Federal do Rio Grande do Norte (PPGSS/UFRN), Natal, RN, Brasil.

Orcid: https://orcid.org/0000-0002-2182-6245

E-mail: carlamontefusco1@gmail.com

Endereço: Universidade Federal do Rio Grande do Norte - Centro de Ciências Sociais Aplicadas

Av. Senador Salgado Filho, 300 - Lagoa Nova - 59072-970, Natal, RN, Brasil 